\title{
Marketing digital como una estrategia para el turismo.
}

\section{Digital Marketing as a strategy for tourism.}

Velasteguí López Efraín. ${ }^{1}$, Sigcha Paola. ${ }^{2}$

DOI: https://doi.org/10.33262/visionariodigital.v1i3.259

\section{Resumen.}

El marketing es el proceso por el que las empresas crean valor para los clientes y construyen fuertes relaciones con los mismos para así obtener el valor de ellos a cambio de satisfacer las necesidades de manera rentable. La Social Media Marketing sirve para promover conversaciones con el mercado y la sociedad, que respeten los principios de la Web Social, y así tener el poder de acceder al sitio web o red social de la empresa para conocer acerca de sus productos y servicios, conocer las opiniones de otros clientes, solicitar información específica, hacer pedidos, pagar online y comentar hacer de su experiencia.

Hoy en día las empresas basan su estrategia de posicionamiento y generación de demanda online. También gestionan sus campañas y estrategias para atraer al usuario y generar nuevas experiencias, las organizaciones deben determinar las necesidades, deseos e intereses de los mercados meta y proporcionar las satisfacciones deseadas de manera más efectiva y eficiente que la de los competidores, de tal manera que mantenga o mejore el bienestar del consumidor y de la sociedad

Cada vez se está más conectados en la tecnología con los dispositivos, en la mayoría de los usuarios pueden ver a distancias las maravillas de los lugares turísticos e interactuar con ellos de manera digital para luego hacerlo real

Palabras claves: Marketing, Marketing 2.0, Marketing Digital, Marketing Touristic, Marketing touristic digital.

\section{Abstract.}

Marketing is the process by which companies create value for customers and build strong relationships with them in order to get value from them in return to meet the needs profitably. Social Media Marketing serves to promote talks with the market and society,

${ }^{1}$ Universidad Técnica de Ambato, Ambato, Ecuador, le.velastegui@uta.edu.ec 2 Universidad Técnica de Ambato.Ambato,Ecuador,paolasigcha@gmil.com 
respecting the principles of the Social Web, and thus have the power to access the website or social network company to know about their products and services, meet the opinions of other clients, request specific information, place orders, pay online and comment on their experience.

Nowadays, companies base their strategy of positioning and generating online demand. Also manage their campaigns and strategies to attract users and generate new experiences, organizations must determine the needs, wants and interests of target markets and provide the desired satisfactions more effectively and efficiently than competitors, so that maintain or improve the welfare of the consumer and society

Every time it is more connected with technology devices, most users can see distances the wonders of tourist sites and interact with them digitally and then make it real

Keywords: Marketing, Marketing 2.0, Digital Marketing, Tourism Marketing, Digital tourism marketing.

\section{Introducción.}

Los problemas de la economía actual se harán más graves debido a los efectos de la inflación, la escasez de recursos, las necesidades, deseos y gustos de los consumidores, los cambios en los mercados, el acelerado desarrollo de las tecnologías y sus cambio significativos y fuertes presiones de la competencia al nivel nacional e internacional. Este ambiente dinámico requiere de un conocimiento avanzado de los principios de las técnicas de mercadotecnia y poseer, además, la adecuada capacidad para la toma de decisiones.

Así, se concibe el marketing o mercadotecnia del turismo como un proceso primario, también conocido como plan de marketing ya que la combinación del concepto de mercadotecnia integra da con el enfoque estratégico se necesita para la aplicación de principios y alcanzar el objetivo propuesto.

\section{Desarrollo}

\section{Marketing Digital}

El marketing en varias investigaciones teóricas realizadas de los siguientes autores (American Marketing Asociation, 2014; Armdtrong, 1966; Klotex, 1931 y Stanton) afirman que el Marketing es un proceso social y administrativo mediante el cual los individuos y grupos obtienen lo que necesitan y desean a través de la creación y el intercambio de productos y de un valor con otros grupos e individuos, a fin de lograr los objetivos de la organización.

Mi criterio respecto a lo investigado que para tener claro el significado de marketing debemos entender que la palabra marketing NO es publicidad o anuncios publicitarios, promociones o rebajas de los productos o ventas ya que también el marketing trabaja con la postventa. 
Nos dicen también que es el proceso social y administrativo por el cual el individuo o grupos obtienen lo que necesitan y desean a través de la creación y el intercambio de productos de valor con otros. También podemos decir que es el conjunto de procesos para la creación, la comunicación, la entrega y el intercambio de ofertas con la que tienen un valor para los clientes, socios y sociedad en general.

Es un sistema netamente de actividades que incluye todas estas mediante las cuales se identifican si son las necesidades o deseos de los consumidores o clientes y estas son necesarias a realizarse y se relacionan unas a otras.

Las actividades más comunes son: Investigación de mercados, Elaboración de planes de marketing,

Participación activa en el desarrollo de productos, Fijación de precios, Selección de los canales de distribución, Implementación de actividades de promoción, Monitoreo y control de todas las actividades del marketing.

En el marketing se debe incluir un conjunto de procesos es decir que todas las actividades que se vayan a realizar deben seguir un orden y satisfacer las necesidades y/o deseos de la menor manera posible. Todas las actividades y procesos del marketing apuntan a:

- Obtener clientes satisfechos con los productos y servicios.

- Generar una utilidad o beneficio para la empresa.

Necesidades, deseos y demanda que deben ser satisfechas con productos y/o servicios, de los cuales serán calificados y tendrán una valor satisfacción por el cliente, de acuerdo con esto existirá el cambio monetario del productos por el valor satisfacción y de esta manera se crea lo que es el mercado.

Las necesidades como mencionaba el autor Klotler, no és más que el estado de carencia percibida ya que solo se puede entender con la pirámide de necesidades de Maslow que se mostrara a continuación,

Gráfico N 1: Pirámide de Necesidades de Maslow.

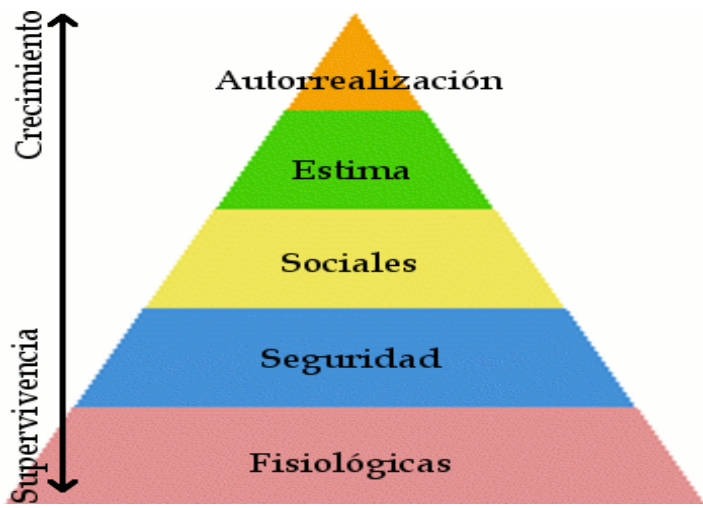

Fuente:https://www.google.com/search?q=piramides+de+necesidades+maslow\&source $=\operatorname{lnms} \&$ tbm $=$ isch\&sa=X\&ved=0ahUKEwimzp2E1rveAhUDuFMKHSSoA0EQ_AUIDi gB\&biw=1366\&bih=662\#imgrc=OJIB7_nU9YI0KM: 
Autor: Abraham Maslow.

El Deseo nos dice que es la forma que adopta una necesidad humana mundiada por la cultura y la personalidad individual por ejemplo: la familia, amigos, sociedad, iglesia moldean tus necesidades convirtiéndola en deseo. Por ejemplo: Las personas en la zona rural satisfacen sus necesidades de hambre con el deseo de frutas o verduras. Las personas en la zona urbana satisface la misma necesidad con otro deseo que puede ser hamburguesa, pizza. De la misma manera pasa con el transporte.

La Demanda no es más que el deseo humano respaldado por el poder de compra, ya que los consumidores ven a los productos como un paquete de beneficios de los cuales escogen el más completo que pueden obtener a cambio de su dinero. Cuando se habla de paquete y beneficios se refiere a productos y servicios.

Los Productos son el conjunto de atributos que se ofrece a un mercado para su atención, adquisición, uso o consumo que se puede satisfacer un deseo o demanda. Por ejemplo, una barra de chocolate.

Los Servicios es la actividad económica que crea valor y proporciona beneficio a los clientes en tiempos y lugares específicos como resultado de producir un cambio de deseo en o a favor del receptor del servicio. Por ejemplo, una grúa. Este producto o servicio será calificado por el cliente según su valor, satisfacción y calidad, este valor se puede entender según el cociente de los beneficios sobre los costos, ya que los beneficios pueden ser funcionales o pueden ser emocionales. Mientras más altos sean los beneficios más menores sean los costos el valor de los productos será mayor satisfecho. El desempeño del producto se ve evaluado según la calidad.

La Calidad es lo primordial que debe existir en el producto ya que es satisfacer las necesidades y expectativas de los clientes. Por ejemplo. Los clientes esperan que un auto Ferrari tenga el interior de cuero y un televisor pero no lo esperar de un Nissan.

El Intercambio es el acto de obtener de un objeto deseado mediante el ofrecimiento de algo a cambio.

La Transacción es el intercambio entre las variables de condiciones acordadas y en el momento y lugar. Por ejemplo, el intercambio de dinero por un televisor lo cual se le denomina transacción monetaria.

Según lo leído puedo entender que de esta manera se crea los mercados con el conjunto de compradores reales y potenciales que tienen una necesidad o deseo que serán satisfechas por este producto.

Ya que el marketing es el proceso por el que las empresas crean valor para los clientes y construyen fuertes relaciones con los mismos para así obtener el valor de ellos a cambio de satisfacer las necesidades de manera rentable. El marketing es fundamental para el éxito de cualquier proyecto empresarial que aspire a ser rentable así mismo debe centrarse a colaborar con el cliente para que juntos se cree nuevas formas de crear valor. 


\section{Marketing 2.0.}

Según la investigación de los siguientes autores (Garcia, 2007; Sanagustin, 2010; Rey Amalio, 2010 y Valzacchi) afirman que la World Wide Web o en su traducción "telaraña de alcance mundial" más conocida como Web es el servicio más "amistoso" para un usuario, tanto nivel avanzado, detrás de esas pantallas cargadas de información de diverso tipo se encuentra una serie de herramientas y estructuras muy complejas en algunos casos, que justamente posibilitan un acceso más transparente.

Se superan las épocas en la que las empresas solo estaban en internet para vender, ahora están en internet para escuchar y participar con sus clientes y clientes potenciales. Conocida así, como una parada virtual donde se ofrece variada información, en el cual los usuarios pueden navegar por diferentes páginas. La Web 1.0 no era social, o al menos no se calificaba así la Web 1.0 era más de lectura y con paginas bastantes estáticas y la 2.0 seria de lectura y escritura con paginas dinámicas de contenidos abiertos; en la 2.0 cualquiera puede crear, la democratización de la edición se hacen más patentes que con el paradigma Web.

En mi criterio puedo decir que el marketing 2.0 o social media marketing sirve para promover conversaciones con el mercado y la sociedad, que respeten los principios de la Web Social, para crear comunidades basadas en la confianza mutua y que las cuales ayuden a construir una identidad fuerte alrededor de la organización.

El marketing 2.0 abre nuevas y diferentes posibilidades de publicidad y mercadeo y mantenerse en constante comunicación con el cliente ya que en el internet las oportunidades son enormes ya que millones de personas se comunican en línea y este marketing aprovecha esta situación. Por ejemplo al publicar información sobre un producto en la web muchas personas pueden visualizarlo y se interesan del producto y así obtener un cliente de acuerdo al valor del producto.

\section{Marketing Digital.}

Según (La Junta de Castilla de León, 2012; Marketing Digital para las Pymes, 2012 y Merodio, 2010) nos manifiestan que el Marketing Digital consiste en usar las tecnologías de información basadas en Internet y todos los dispositivos que permitan sus acceso para realizar comunicación, ya que también se puedes armar estrategias desde medios convencionales (televisores, radios, mensajes de texto, etc.) y a través de canales que usen internet como medios sociales, anuncios digitales, sitios web, aplicaciones clásicas y móviles con intención comercial entre una empresa y sus clientes o potenciales clientes.

En mi criterio puede expresar que el Internet es la nueva herramienta del marketing, no usarla es una amenaza y usarlas una oportunidad en este mundo digitalizado. Las personas consideran al internet como una fuente global de información, las antiguas páginas amarillas ahora son remplazadas por sitios web. 
Internet y Marketing fusionados, crean un arma útil para las empresas, es decir que las Tecnologías de Información y Comunicación (TIC's) junto con el marketing mejoran las posibilidades de comercio, abren nuevos espacios a clientes, clientes potenciales y un posicionamiento de marca exitoso.

Las actitudes son las siguientes:

- El cliente es más independiente.

- El cliente está más y mejor informado (buscan y comparan más).

- No perdonan los fallos.

- El cliente está cada vez más habituado a utilizar Internet en sus procesos de compra.

Por lo que el cliente tiene el poder y la empresa la facultad de complacerlo. Buscando nuevas formas y maneras para que se sientan respaldado, identificado y satisfecho en la compra de un producto.

Gracias a los avances en tecnología con el pasar del tiempo las personas podemos utilizar la amplia gama de aparatos electrónicos como: computadoras de escritorio y personales, tablets, teléfonos móviles inteligentes, televisores inteligentes, consolas de videojuego, etc.

En todos los aparatos electrónicos se utilizan programas o software y aplicaciones con la finalidad de crear, editar, compartir textos, imágenes, audios y videos. Ya que gracias al internet tenemos la posibilidad de poder estar conectados y así tener acceso a todo lo anterior de cualquier parte durante las 24 horas del día y comunicarnos con una o varias personas al mismo instante.

El marketing encontró nuevas y valiosas herramientas por lo tanto una nueva manera o modo para comunicarse, brindar servicios a los clientes y realizar actividades de venta a este tipo de marketing se le conoce como marketing digital.

Así que se puede decir que este marketing tiene un tipo de marketing cuya función es mantener conectada a la empresa u organización con los segmentos de mercado y clientes, mediante los medios digitales que estén disponibles, con la finalidad de comunicarse con ellos y brindarles servicios y realizar actividades de venta.

Los segmentos de mercado nos dice que son los grupos de personas, empresas u organizaciones que suelen responder de forma similar a determinadas acciones de marketing, porque tienen características homogéneas en cuanto a deseo de preferencia de compra en el uso de productos pero distintas de las que tienen otros segmentos que pertenecen al mismo mercado.

El Cliente es una persona, empresa u organización que desea adquirir o comprar de forma voluntaria un producto y/o servicio que necesita o desea para sí mismo o para otras personas, empresas u organizaciones. 
El Medio digital es todo aquel contenido que se caracteriza por incluir audio, video, imágenes y textos y los mismos se pueden reproducir, distribuir y transmitir.

El marketing digital favorece una comunicación fluida porque utiliza medios digitales que posibilitan una conexión con el segmento de mercado o público en cualquier momento y lugar para transmitir mensajes, información, datos, ideas y avisos y mejor aún para buscar interactuar con ese público objetivo para recibir sus puntos de vista, comentarios, opiniones, experiencias y sugerencia.

El marketing digital es útil para brindar servicios mediante los medios digitales ya que se pueden prestar servicios:

- Servicios pre-venta.- responder a consultar y brindar asesoramiento en general mediante chats, correos electrónicos, foros y blogs.

- Servicios post venta.- recepción y solución de reclamos, descarga de software para una mejor utilización de los productos, descarga de manuales de uso entre otros.

Las herramientas más útiles del marketing digital: Sitios Web, Blogs, Redes Sociales (Facebook, Twitter, YouTube), Buscadores (Google, Yahoo), Correo electrónico, Juegos en línea (Consolas de videojuego), Aplicaciones para móviles dispositivos móviles (App), Mensajes a dispositivos móviles (SMS), Anuncios de distintos formatos.

Podemos acceder al sitio web o red social de la empresa para conocer acerca de sus productos y servicios, conocer las opiniones de otros clientes, solicitar información específica, hacer pedidos, pagar online y comentar hacer de su experiencia. Estar conectados en la web siempre será fundamental para el éxito en los negocios sin fines de lucro en general de las relaciones humanas. Por lo tanto el marketing digital no es una opción a considerarse al contrario la planificación e implementación es un asunto clave para que tocada empresa, organización puede tener la oportunidad en su mercado.

\section{Marketing Turístico.}

Estos autores Aragay, J., \& Grande, A. (2010) nos dice que la economía constituye una de las fuerzas ambientales de más peso en el sistema moderno de marketing turístico. En consecuencia, la actividad turística es participante en primer orden del sistema económico digital en todos sus componentes: atracciones, el turista consumidor, la comunidad receptora y/o emisora de turista, los servicios de transporte en todas sus formas y alojamiento y servicios de alimentación.

Al respecto la existencia de páginas web y de los correos electrónicos, permite:

1. Intercambiar informaciones completas e inclusive verificar oportunidades para viajar con el paquete turístico.

2. Verificar tarifas de viajes chárter o individuales, hacer reservaciones, efectuar los pagos incluyendo formas de financiamiento. 
3. Obtener información de la región o país hacia el cual se viaja en forma personal y no a través de los intermediarios. Incluyendo principales atracciones.

4. Paisajes naturales, vegetación, clima, población, idiomas, servicios básicos y complementarios.

5. Las páginas Web de las cadenas hoteleras permiten obtener, la información sobre tarifas, descuentos en temporadas y noveles de ocupación, una visión completa de las instalaciones y servicios de los establecimientos que les son ofrecidos a los turistas para su alojamiento y servicios hoteleros complementarios.

6. El software de Rosenbluth aparece como una solución para la supervivencia de los agentes de viajes.

7. En la economía digital, los intermediarios necesitan recorrer la cadena alimentaria (red digital del valor) en la búsqueda de nuevas formas de crear valor para los clientes.

Según lo investigado puedo expresar que antes la tecnología en el viaje y las vacaciones no tenían mucha relación ya que por lo general compramos un viaje recolectando información de amigos y familiares que en algún momento visitaron el lugar turístico, ya sea playa o ciudad, también recolectábamos información de diarios, revistas y folletos o a una agencia de viajes para que nos indiquen a qué lugar ir, que excursiones hacer. Con el pasar del tiempo apareció el Internet y aparecieron las herramientas digitales como buscadores, sitios web específicos de proveedores de turismo y las redes sociales.

Hoy en día las empresas basan su estrategia de posicionamiento y generación de demanda online. También gestionan sus campañas y estrategias para atraer al usuario y generar nuevas experiencias, ya que el usuario selecciona el destino, realiza la compra online y deja un comentario.

\section{Marketing turístico en el Ecuador.}

De acuerdo a datos del Ministerio de Turismo (2014) el país desarrolló"11 líneas de productos: circuito generales, sol y playa, turismo comunitario, parque temático, ecoturismo y turismo de naturaleza, turismo de deporte y aventura, turismo de salud, agroturismo, MICE (Reuniones, incentivos, congresos, Convencionales y Exhibiciones) y cruceros", por lo que en estas áreas principalmente las pymes se han potenciado.

Para ser más específicos la misma entidad, Ministerio de Turismo afirma que:

Los circuitos turísticos generales son el primer producto turístico más comercializado, constituyendo un $46 \%$ de la oferta, el ecoturismo es el segundo constituyendo un $21 \%$, los cruceros (principalmente a las Islas Galápagos) son el tercer productos turístico más comercializado representado un $13 \%$ y finalmente, el turismo cultural es el cuarto producto turístico más comercializado representado el $7 \%$. 
Gráfico N 2: Principales productos de Turismo en el Ecuador.

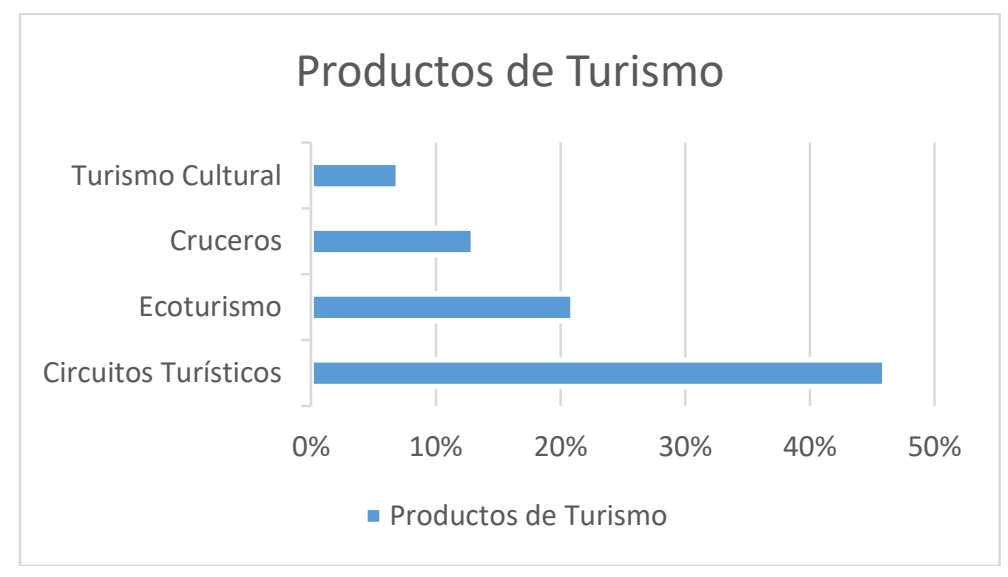

Fuente: Elaboración propia a partir de los datos del Ministerio del Ecuador.

Según lo investigado puedo decir que de acuerdo a los datos estadísticos representan un importante indicador con respecto a la gestión, creación e impulso de nuevos negocios en el país, ya que de esta manera los futuros empresarios poseen un panorama más claro de las preferencias de los clientes y de sus proyecciones del consumo al momento de empezar a vivir la experiencia turística.

Cabe destacar que el microempresario ecuatoriano requiere de competencias y conocimientos importantes para pertenecer a este sector, tales como habilidades de comunicación, idiomas, capacidad de servicio, así como contactos en diversas áreas que faciliten la experiencia del turista en el Ecuador.

\section{Marketing turístico digital.}

Según (Machin, 2001; Suvite,2013)nos manifiestan que el marketing turístico permite conocer y comprender el mercado, para llegar a conformar una oferta realmente atractiva, variada, capaz de obtener clientes dispuestos a consumir el producto o servicio y mantener fidelidad al mismo .

En mi criterio puedo decir que la actividad turística ha mostrado un gran desarrollo a nivel mundial, asociado principalmente a factores tecnológicos, la mayor competitividad obliga a las empresas del sector a desarrollar nuevas tecnologías que permitan la reducción de costos, ajuste de precios y creación de productos más imaginativos y ajustados a las necesidades de los clientes que se presentan cada vez más exigentes.

El marketing no depende únicamente del área de marketing, ventas o relaciones públicas, ésta es una labor compleja, dada la heterogeneidad de las actividades turística y los diversos componentes que influyen en la satisfacción de un turista. La organización debe determinar las necesidades, deseos e intereses de los mercados meta y proporcionar las satisfacciones deseadas de manera más efectiva y eficiente que la de los competidores, de tal manera que mantenga o mejore el bienestar del consumidor y de la sociedad". 


\section{Turismo en el Ecuador.}

Según (Ecuador inmediato, 2012) menciona que el desarrollo turístico del país formara parte de la edición de la revista "The Business Year 2012", los grandes sectores como economía, finanzas, turismo. Industrias, energía, agricultura, transporte y otros, serán analizados en esta edición dedicada al Ecuador, para promover una visión completa del país en su entorno empresarial, mostrar las oportunidades que tienen los potenciales, inversores y fomentar el comercio internacional. Con este propósito la revista con la OMT de ese entonces el ministro de turismo Freddy Ehlers Zutita y conoció los proyectos y planes que se ejecutan en esta Cartera de Estado parar apuntar en crecimiento del sector turístico y económico del Ecuador.

Según (El Ministerio de Turismo Ecuador) Afirma que Ecuador recibido más de 180 premios de reconocimientos relacionados al turismo, en el sector público y privado. Entre 2007 y la primera semana del 2017, y está en el top de países del mundo para retirarse.

Además la revista International Living Magazine ha reconocido durante 10 años consecutivos a Ecuador como uno de los mejores países del mundo para vivir, ya que algunas de sus ciudades como Quito y Guayaquil han recibido otros reconocimientos importantes por su calidad de vida.

Se detecta los movimientos de turistas locales y extranjeros, con características y perfiles con la fuente de referencia de INEC.

También encontramos datos proporcionados por el ministerio de turismo que se ponderan cifras acerca de la satisfacción del turista, en el gasto, motivos de viaje, planificación previa la determinación de los destinos. Así como en agosto de 2014 ingresaron 131.694 extranjeros con una variación de 17\% por lo que en anterior año 2013 ingresaron un total de 112.569 turistas. Lo cual quiere decir que el Ecuador es cada vez más atractivo para que incremente el turismo, con un mejor servicio calificado.

Gráfico N 3: Incremento de Turistas Extranjeros en el Ecuador.

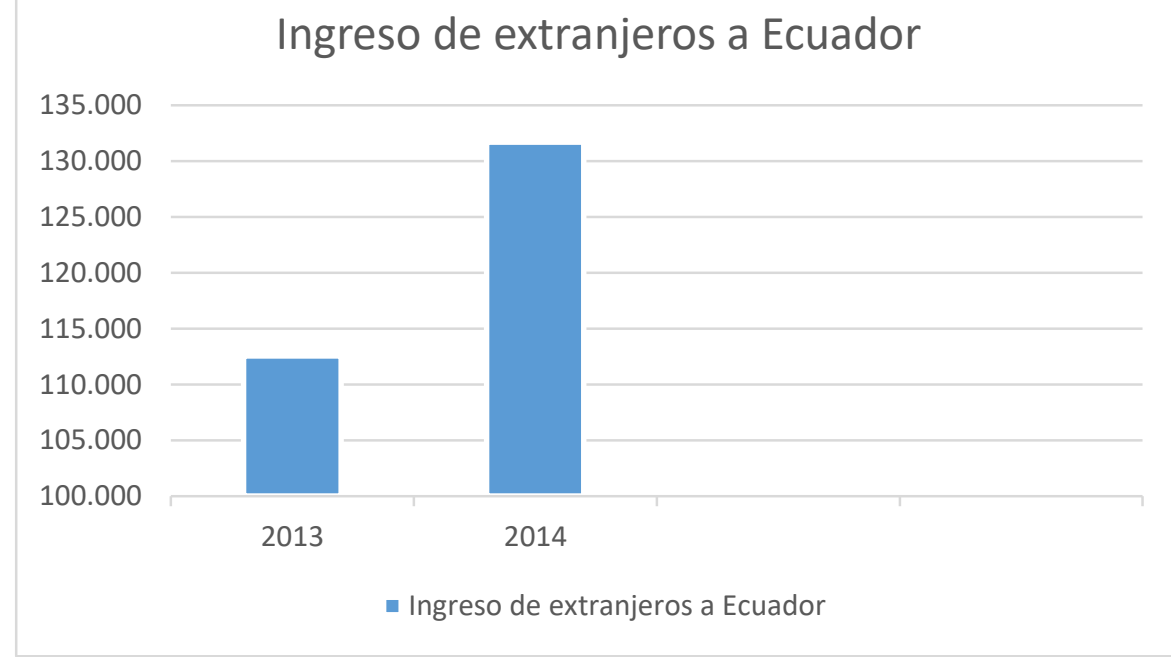

Fuente: Elaboración propia a partir de datos del Ministerio del Ecuador. 


\section{Estrategias digitales para el turismo.}

Cada vez se está más conectados en la tecnología con los dispositivos, en la mayoría de Los usuarios pueden ver a distancias las maravillas de los lugares turísticos e interactuar con ellos de manera digital para luego hacerlo real.

La clave para tener éxito en las redes sociales es empatizar con los usuarios y hacerles sentir que te preocupas por ellos y darles información que están buscando de cierto destino.

\section{La transformación Digital y el impacto en el sector turismo.}

Según los autores (Bustamante y Prieto, 2015) nos manifiestan que el turismo cultural crece rápidamente, con enormes posibilidades frente al turismo indiferenciado de masas pero también con riesgos sobre la preservación del patrimonio artístico y urbano, las NTIC se revelan como una potente herramienta para el turismo sostenible.

En mi criterio puedo decir que los medios digitales están cambio al mundo a las empresas y sobre todo al sector del turismo, los beneficios de esta revolución son la mejora de la competitividad, la rentabilidad y una relación más cercana al cliente.

Por ejemplo: el sector del turismo que lidera con el $13.2 \%$ de participación en el comercio electrónico. Si quieres buscar hoteles Facebook es la red social más usada y twitter es la red social de mayor cantidad de seguidores.

Los hoteles pequeños aún no se dan cuenta que los canales digitales son más prácticos para llegar al consumidor, apenas el $20 \%$ tiene presencia en redes sociales como Facebook, Twitter, Instagram, etc. dejando de lado a miles de potenciales de clientes.

Los ejes de transformación en el sector turístico:

Cloud almacena datos y permite la creación de plataformas tecnológicas que ofrece servicios de forma más rápida y eficiente. Desarrollo de las plataformas hoteleras como Booking, Trivago que permiten al cliente informarse, reserva y pagar por la Internet.

Se han convertido en la oportunidad de negocios los móviles o teléfonos inteligentes.

El internet de las cosas es una innovación tecnológica que brinda mejoras en el servicio como por ejemplo las experiencias innovadoras en el mercado.

Social y economía colaborativa una buena gestión en las redes sociales fortalece el dialogo entre las empresas y sus consumidores generando canales de comunicaciones con el cliente, reputación online y escuchas activa, redes sociales especializadas, intercambio de bienes y servicios compartidos.

La transformación digital permite al turismo superar barreras y convertirlas en nuevas tendencias en una oportunidad de negocios. 


\section{Conclusión.}

Las empresas descubrieron que este nuevo medio permitía realizar importantes negocios, por lo que comenzaron a orientar sus esfuerzos en tratar de comprender su funcionamiento y de encontrar los mejores caminos para llegar a los consumidores potenciales que navegan diariamente en la red.

El marketing digital es una de las herramientas muy claves para el éxito de la empresa y esencial para la promoción y comercialización del turismo activo, ya que el mismo debe cumplir los requisitos de desestacionalizado y sostenible para el turismo.

Las redes sociales y la web tiene un mayor alcance de cobertura mucho mayor al de los medios tradicionales por lo tanto el alcance que una marca puede llegar a ser muy satisfactorio.

Las empresas del sector turístico deben tener en cuenta que una estrategia digital no solo se realiza en temporadas, han ido aumentando su crecimiento en las distintas tecnologías desarrolladas a lo largo del tiempo. Estas herramientas han introducido importante beneficios, no solo en la reducción de costos, sino también en cuanto a la optimatización tanto de las operaciones internas como de los recursos productivos de la empresa, aumentando de esta manera su eficacia y eficiencia.

\section{Bibliografía.}

Altes Machín \& Carmen. (2001). Marketing y Turismo: Introduciion al marketing y destinos turisticos. Madrid: Sintesis.

American Marketing Association. . (2014). Marketing Power. Obtenido de https://www.ama.org/Pages/default.aspx

Aragay J. \& Grande A. (1978). Marketing Turistico. Madrid: Servicios Editoriales y de Empresa. S.A.

Diego Monferrer Tirado. (2013). En Fundamentos del marketing. 1ra Edición. (pág. 20). España: Universidad de Jaume.

Ecuador inmediato. (2012). El Desarrollo Turistico. The Business Year 2012.

Garcia A. (2007). ¿Web 2.0 vs Web 1.0? España: Boletin Electronico de Noticias de Educacion a Distancia (BENED).

Junta de catillas de León. (2012). Marketing Digital para las Pymes. España.

Kotler,Phipli;Dipak Jain \& Maesincee, Suvite. (2013). El marketing se mueve: Una nueva aproximacion a los beneficios, el crecimiento y la renovación. Buenos Aires: Sintesis S.A. 
Merodio J. (2010). Marketing en redes sociales. Obtenido de http://www.emprendepyme.net/marketing-en-redes-sociales-social-media-parapymes.html

Michael J. Etzel, William J. Stanton.\& Bruce J. Walker. (s.f.). Funfamentos de Marketing (14va Edición). Mexico: Mc Graw Hill.

Philio Kloter, G. A. (s.f.). Fundamentos del Marketing. Octava Edicion. Mexico: Pearson Educacion.

Enrique Bustamante \& Jesús Prieto (2015). TELOS 102: Turismo, Patrimonio y NTIC. Fundación Telefónica.

Philip Klotex 1931 \& Gary Armdtrong 1966. (s.f.). Fundamentos del Marketing Octava Edición. Mexico.

Rey Amalio. (2010). Marketing 2.0. Obtenido de http://www.amaliorey.com/2010/03/29/marketing-2.0-\%C2\%BFy-eso-que-espost-152/

Sanagustin E. (2010). Marketing 2.0. Obtenido de http://books.google.com.ec/books?id=TP_kPFmZZkkC\&printsec=frontcover\&d $\mathrm{q}=$ marketing $\% 202.0 \& \mathrm{f}=$ false

Ministerio de Turismo. (2014). Plan Integral de Marketing Turístico de Ecuador.

Quito: Ministerio de Turismo.

Valzacchi. (s.f.). La Web Wide Web en Valzacchi. Obtenido de http://www.educoas.org/portal/bdigital/contenido/ValzacchiCapitulo-2New.pdf

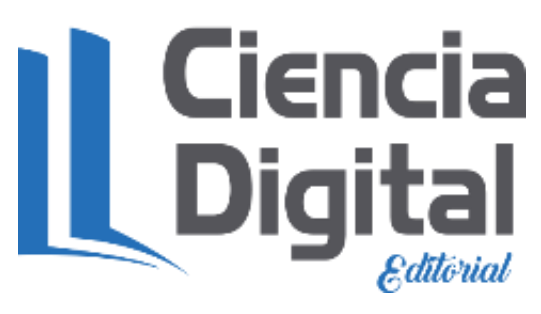




\section{Para citar el artículo indexado.}

Velasteguí E \& Sigcha P. (2018). Marketing digital como una estrategia para el turismo. Revista electrónica Visionario Digital 1(1), 19-33. Recuperado desde: http://cienciadigital.org/revistacienciadigital2/index.php/VisionarioDigital/article/view/ $259 / 562$

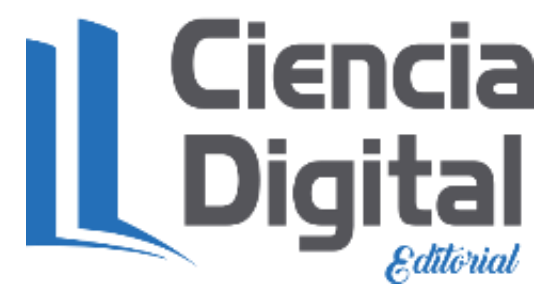

El artículo que se publica es de exclusiva responsabilidad de los autores y no necesariamente reflejan el pensamiento de la Revista Ciencia Digital.

El articulo queda en propiedad de la revista y, por tanto, su publicación parcial y/o total en otro medio tiene que ser autorizado por el director de la Revista Ciencia Digital.
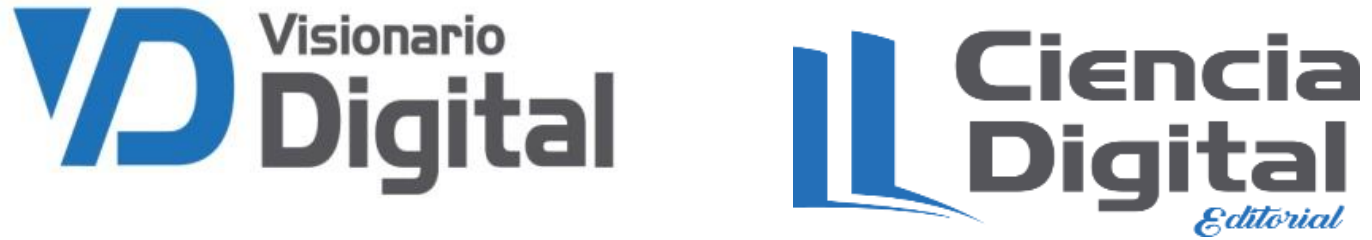